\title{
Prognostic implications of decreased microRNA-101-3p expression in patients with non-small cell lung cancer
}

\author{
HAI-MIN LU ${ }^{1 *}$, WAN-WAN YI ${ }^{2 *}$, YU-SHUI MA ${ }^{2,3^{*}}$, WEI WU ${ }^{4 *}$, FEI YU ${ }^{2 *}$, HENG-WEI FAN ${ }^{5}$, \\ ZHONG-WEI LV ${ }^{2}$, HUI-QIONG YANG ${ }^{6}$, ZHENG-YAN CHANG ${ }^{6}$, CHAO ZHANG $^{5}$, WEN-TING XIE ${ }^{2}$, \\ JUN-JIAN JIANG ${ }^{7}$, YING-CHUN SONG ${ }^{2}$, LI CHAI ${ }^{2}$, CHENG-YOU JIA $^{2}$, GAI-XIA LU ${ }^{2}$, XIAO-JUN ZHONG ${ }^{8}$, \\ LI-KUN HOU ${ }^{4}$, CHUN-YAN WU ${ }^{4}$, MIN-XIN SHI ${ }^{1}$, JI-BIN LIU $^{1}$ and DA FU ${ }^{9}$ \\ ${ }^{1}$ Department of Thoracic Surgery, Nantong Tumor Hospital, Nantong, Jiangsu 226631; ${ }^{2}$ Department of Nuclear \\ Medicine, Shanghai Tenth People's Hospital, Tongji University School of Medicine, Shanghai 200072; ${ }^{3}$ Shanghai \\ Engineering Research Center of Molecular Therapeutics and New Drug Development, College of Chemistry and \\ Molecular Engineering, East China Normal University, Shanghai 200062; ${ }^{4}$ Department of Pathology, Shanghai \\ Pulmonary Hospital, Tongji University School of Medicine, Shanghai 200433; ${ }^{5}$ Department of Hepatic Surgery I, \\ Eastern Hepatobiliary Surgery Hospital, Second Military Medical University, Shanghai 200438; ${ }^{6}$ Department of \\ Pathology, Shanghai Tenth People's Hospital, Tongji University School of Medicine, Shanghai 200072; ${ }^{7}$ Department \\ of Hand Surgery, Huashan Hospital, Fudan University, Shanghai 200040; ${ }^{8}$ Department of Oncology, The First \\ Affiliated Hospital of Nanchang University, Nanchang, Jiangsu 330006; ${ }^{9}$ Central Laboratory for Medical Research, \\ Shanghai Tenth People's Hospital, Tongji University School of Medicine, Shanghai 200072, P.R. China
}

Received January 25, 2018; Accepted August 21, 2018

DOI: $10.3892 / \mathrm{ol} .2018 .9559$

\begin{abstract}
To investigate the expression level of microRNA-101-3p (miR-101-3p) and its possible association with progression, prognosis and chemotherapy in patients with non-small cell lung cancer (NSCLC), the Gene Expression Omnibus (GEO) database was used. Quantitative polymerase chain reaction was used to verify the expression in 327 NSCLC and 42 adjacent normal lung tissues, of which 42 viable tissues were paired with nearby normal lung tissues. Based on the Cox regression model, univariate and multivariate analyses were used to address the factors that had effects on overall survival (OS) and disease-free survival (DFS) rate. Data from the GEO database demonstrated that the miR-101-3p expression in NSCLC was downregulated, compared with normal lung
\end{abstract}

Correspondence to: Dr Ji-Bin Liu, Department of Thoracic Surgery, Nantong Tumor Hospital, 48 West Qingnian Road, Nantong, Jiangsu 226631, P.R. China

E-mail: tians2008@163.com

Dr Da Fu, Central Laboratory for Medical Research, Shanghai Tenth People's Hospital, Tongji University School of Medicine, 301 Middle Yanchang Road, Shanghai 200072, P.R. China

E-mail: fu800da900@126.com

*Contributed equally

Key words: microRNA-101-3p, non-small cell lung cancer, overall survival, disease-free survival, prognosis cancer. Survival analysis through univariate and multivariate models indicated that the miR-101-3p expression level was a crucial risk factor for OS and DFS in patients with NSCLC. A number of clinical parameters were determined to be associated with miR-101-3p expression, including tumor diameter, lymph node metastasis and tumor-node-metastasis stage. Adjuvant chemotherapy with high expression of miR-101-3p was determined to increase OS and DFS in patients with NSCLC, compared with patients with de novo or low expression of miR-101-3p. The present results demonstrated that miR-101-3p expression levels were associated with NSCLC progression and prognosis, which indicated that miR-101-3p may serve as a biomarker for patients with NSCLC who have received adjuvant chemotherapy.

\section{Introduction}

Lung cancer is the most frequently diagnosed cancer and was reported in 2015 as the leading cause of cancer-associated mortalities globally, as its incidence and mortality rate have been increasing in numerous countries, including China (1). Of the lung cancer instances, $\sim 80 \%$ are non-small cell lung cancer types (NSCLC), which are clinically and pathologically different from SCLC types (2). Treatment options for lung cancer include surgery, radiation therapy, chemotherapy and targeted therapy. Therapeutic modalities depend on a number of factors, including the type and stage of cancer (3). Despite ongoing therapeutic efforts, patients with lung cancer have a poor prognosis with an arithmetic average 5-year survival rate of $15 \%$ (4). This is primarily due to inadequate knowledge regarding tumor progression and its associated molecular 
alterations, which delay diagnosis (5); therefore, improvements in molecular genetics diagnosis and prediction of prognosis for targeted treatments and clinical decisions are required.

microRNAs (miRNAs) are a class of non-coding single stranded RNA molecules of 22 nucleotides, which are encoded by endogenous genes (6). miRNAs are important regulators of gene expression in plants and animals (7). Recent studies have determined that miRNAs are associated with the formation and suppression of tumors (8-10). Changes in miRNA expression may serve an essential role in tumorigenesis and cancer inhibition. A number of miRNAs act as tumor suppressors, while others stimulate tumor growth. For example, there is reduced miR-143 expression in patients with colorectal cancer (11), miR-15-a and miR-16-1 are reduced in patients with B cell chronic lymphocytic leukemia (12), precursor miR-155 is highly expressed in Burkitt lymphoma, and the miR-17/92 cluster has been determined to be highly expressed in lung cancer, particularly in patients with SCLC $(13,14)$. Additionally, miR-608 regulates apoptosis in human lung cancer via the regulation of AKT serine/threonine kinase (Akt)2, and miR-99a suppresses the invasion and migration of NSCLC cells (15). miR-101-3p is a member of the miR-101 family, and a recent study indicated that it has tumor suppressor effects in patients with NSCLC (16). However, to the best of our knowledge, a limited number of studies have addressed the association between miR-101-3p and adjuvant chemotherapy in patients with NSCLC (17-19).

In the present study, the miR-101-3p expression was investigated using the Gene Expression Omnibus (GEO) database and the expression levels of miR-101-3p in NSCLC tissues was evaluated using quantitative polymerase chain reaction (qPCR). Additionally, the association between miR-101-3p and prognosis following adjuvant chemotherapy was investigated in patients with NSCLC.

\section{Materials and methods}

Compliance with ethical standards. The present study was approved by the Ethics Committee of Shanghai Tenth People's Hospital, Tongji University School of Medicine (approval no. SHSY-IEC-pap-15-18; Shanghai, China). Each participant provided signed informed consent prior to participate in the present study. Patients or their legal surrogates provided signed informed consent for the surgical procedures. All specimens were handled and anonymized according to ethical and legal standards.

miRNA expression in NSCLC from the GEO database. The expression levels of miRNAs were assessed in NSCLC tissues and normal tissue samples from the GEO database (http://www. ncbi.nlm.nih.gov/geo/) (20-23) using the following keywords: 'Homo sapiens'; 'NSCLC' and 'miRNA'. All datasets used the Illumina or Agilent Array platform to detect signals. For quality control, exclusion criteria for probes were as follows: i) had a low bead count of $<3$ in at least $5 \%$ of samples and ii) indicated a detection-P $>0.05$ in at least $5 \%$ of samples (20). The raw data set GSE61741 (21) was downloaded, which provided the peripheral blood miRNA profiles from 94 healthy controls and 73 patients with lung cancer. Additionally, GSE24709 (22) (including 19 healthy controls and 28 patients with lung cancer) and GSE56036 (23) (including 29 health controls and 23 patients with NSCLC) were downloaded in the GEO datasets to identify differentially expressed miRNAs in NSCLC samples and adjacent non-tumor tissues. Fold change $(\mathrm{FC} \geq 2)$ and $\mathrm{P}<0.05$ served as basic screening parameters. Hierarchical clustering was performed using the multiple experiment viewer 4.7.1 software programs (http://www.tm4.org/).

Clinical specimens. A total of 327 lung cancer tissues were collected from 206 male patients and 121 female patients with lung cancer who underwent surgery in Shanghai Tenth People's Hospital of the Tongji University School of Medicine (Shanghai, China) between January 2004 and December 2016. Inclusion criteria consisted of the following: $\leq 75$ years with histologically proven NSCLC; no severe major organ dysfunction; World Health Organization (WHO) performance status of 0 or 1 and no prior cancer chemotherapy. Exclusion criteria consisted of the following: Age $\geq 76$; severe major organ dysfunction; WHO performance status of $>1$ or prior cancer chemotherapy. Clinical information of the patients were recorded, including sex, age, smoking history, the diameter and differentiation of the tumor, lymph node metastasis, stage of Tumor-Node-Metastasis (TNM), histological grade, degree of invasion of the lung membrane, degree of vascular invasion, whether chemotherapy had been administered, overall survival (OS) rate, disease-free survival (DFS) rate and miR-101-3p expression status. Each participant provided signed informed consent prior to participation in the present study. Patients or their legal surrogates provided signed informed consent for the surgical procedures.

RNA extraction and detection of miR-101-3p expression by $q P C R$. RNA, including miRNAs, from NSCLC and normal tissue samples, were extracted using TRIzol ${ }^{\circledR}$ reagent (Thermo Fisher Scientific, Inc., Waltham, MA, USA), according to the manufacturer's protocols and an optimized protocol (13). RNA concentration was measured using NanoDrop ND-1000 (Thermo Fisher Scientific, Inc.) and the quality was assessed using electrophoresis in $1.5 \%$ denaturing agarose gels and viewed on a Kodak Gel Logic 2200 imaging system (Kodak, Rochester, NY, USA). TaqMan probe-based qPCR was carried out using a commercial kit (cat. no., A25576; Applied Biosystems; Thermo Fisher Scientific, Inc.), according to the protocol of the manufacturer (24). RT reactions were performed using AMV Reverse Transcriptase (Takara Biotechnology Co., Ltd., Dalian, China) and qPCR was performed using a standard TaqMan PCR kit protocol on the Applied Biosystems 7900HT Sequence Detection system (Thermo Fisher Scientific, Inc.), according to the manufacturer's protocols. qPCR for miR-101-3p was executed using the TaqMan ${ }^{\circledR}$ universal PCR kit (Thermo Fisher Scientific, Inc.), according to the manufacturer's protocols. Thermocycling conditions were as follows: Initial denaturation at $94^{\circ} \mathrm{C}$ for $10 \mathrm{~min}$, followed by 35 cycles of $94^{\circ} \mathrm{C}$ for $30 \mathrm{sec}, 60^{\circ} \mathrm{C}$ for $30 \mathrm{sec}$ and $72^{\circ} \mathrm{C}$ for $30 \mathrm{sec}$, with a final extension at $72^{\circ} \mathrm{C}$ for $10 \mathrm{~min}$. Each reaction was independently tested in duplicate at a minimum of three times. The following primers were used: miR-101-3p, forward, 5'-GGT CACTAAGGCGGT-3' and reverse, 5'-CAGTCGTTGCGT CGGAGT-3'; U6, forward, 5'-CTGGTTAGTACTTGGACG GGAGAC-3' and reverse, 5'-GTGCAGGGTCCGAGGT-3'. U6 was used as the endogenous control and the $2^{-\Delta \Delta \mathrm{Cq}}$ method was used to analyze expression levels (25). 
A

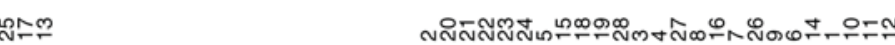

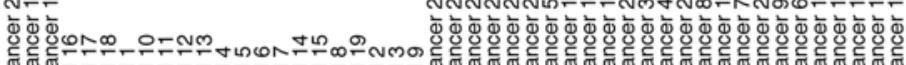

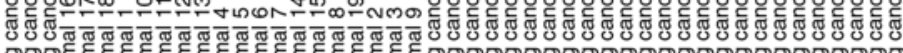

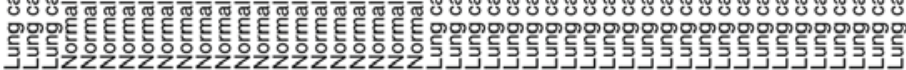
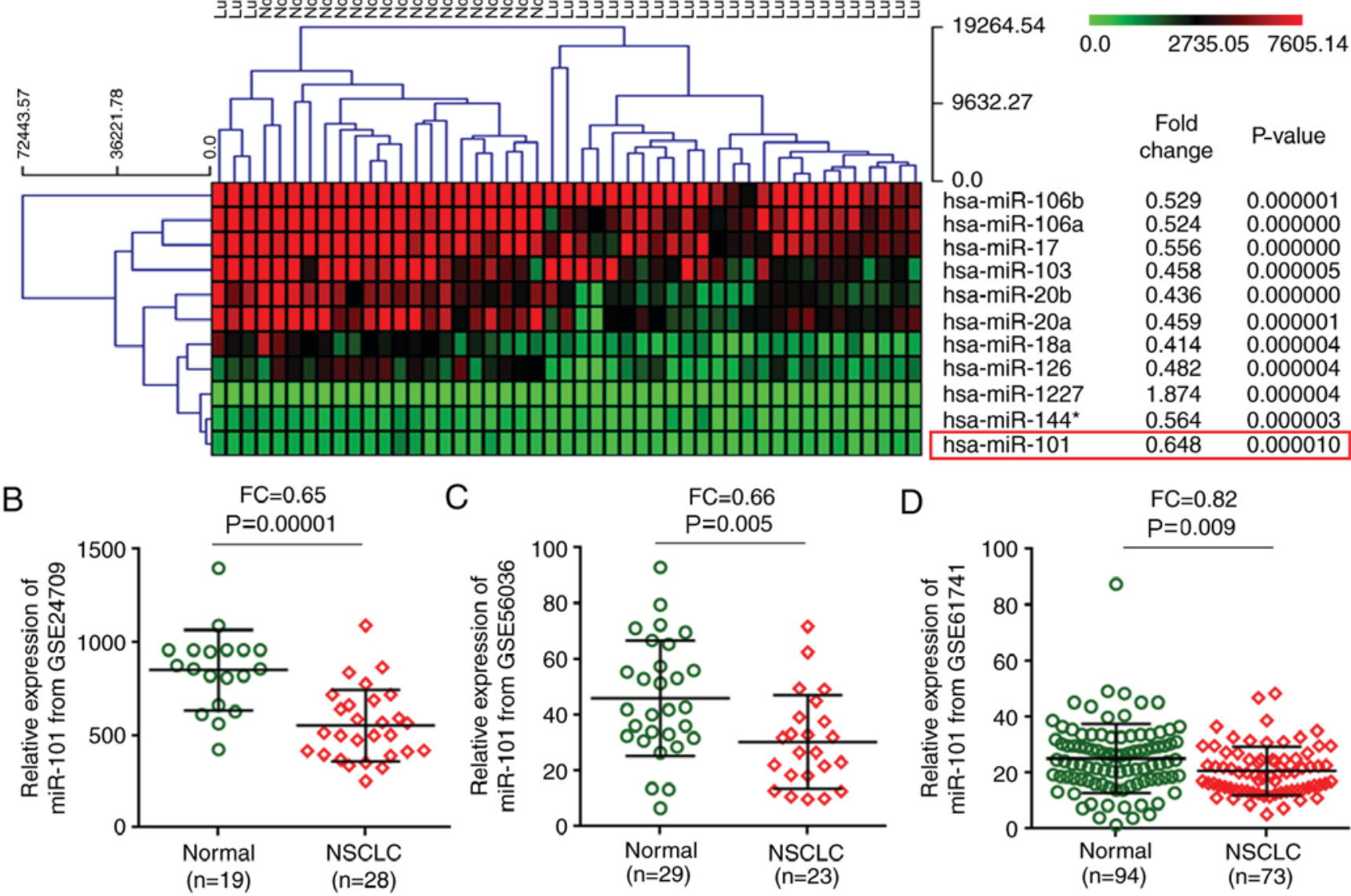

Figure 1. Analysis of miR-101-3p expression in NSCLC using the GEO database. (A) Data from the GEO dataset (GSE24709) was clustered using the multiple experiment viewer 4.7.1 software. (B) The miR-101-3P expression level in normal tissues, compared with NSCLC tissues, from the GEO database (GSE24709). (C) The miR-101-3p expression level in normal tissues, compared with NSCLC tissues, from the GEO database (GSE56036). (D) The miR-101-3p expression level in normal tissues, compared with NSCLC tissues, from the GEO database (GSE61741). miR, microRNA; NSCLC, non-small cell lung cancer; GEO, Gene Expression Omnibus; FC, fold change.

Statistical analysis. Expression levels of miR-101-3p were summarized and presented as the mean \pm standard deviation. All statistical analyses were performed with IBM SPSS statistics software version 20.0 for Windows (IBM Corp., Armonk, NY, USA). The paired Student's t-test was used to determine the difference between two groups of data. The $\chi^{2}$ test was used to evaluate the differences among groups. Kaplan-Meier estimator curves and the log-rank test were performed to analyze the OS or DFS of patients with NSCLC. Hierarchical clustering was performed using the multiple experiment viewer 4.7.1 software programs: (http://www. $\mathrm{tm} 4 . \mathrm{org} / \mathrm{mev} /$ ), according to the manufacturer's protocols. Univariate and multivariate Cox proportional hazards regression models were used to investigate the multiple characteristics associated with the prognosis of patients with NSCLC. $\mathrm{P}<0.05$ was considered to indicate a statistically significant difference.

\section{Results}

Expression of miR-101-3p using the GEO database and clustering analysis. Firstly, miR-101-3p expression analysis was performed using data from the GEO database. GSE24709 included the miRNA profile in peripheral blood samples from patients with lung diseases and healthy controls. The present analysis demonstrated that miR-101-3p expression in NSCLC tissues was significantly reduced, compared with non-tumor tissue (FC, 1.5; P<0.00001; Fig. $1 \mathrm{~A}$ and B). The miR-101-3p expression was validated in NSCLC tissues in two datasets (GSE56036 and GSE61741) and indicated that miR-101-3p levels were significantly reduced in NSCLC tissues, compared with normal tissues $(\mathrm{P}=0.005$, Fig. $1 \mathrm{C}$; $\mathrm{P}=0.009$, Fig. 1D).

miR-101-3p expression in NSCLC and adjacent non-tumor tissues. Expression of miR-101-3p was evaluated in NSCLC samples ( $\mathrm{n}=327)$ and compared with adjacent non-tumor tissue $(n=42)$ by qPCR. The present results indicated that miR-101-3p expression levels were significantly reduced in NSCLC tissues, compared with adjacent non-tumor tissues (FC, 0.36; $\mathrm{P}=0.002$; Fig. 2A). The level of miR-101-3p expression was $0.72 \pm 0.04$ in 327 NSCLC tissues, which was significantly reduced compared with normal tissues $(n=42 ; 1.28 \pm 0.16)$ (FC, 0.56; P=0.117; Fig. 2B). 

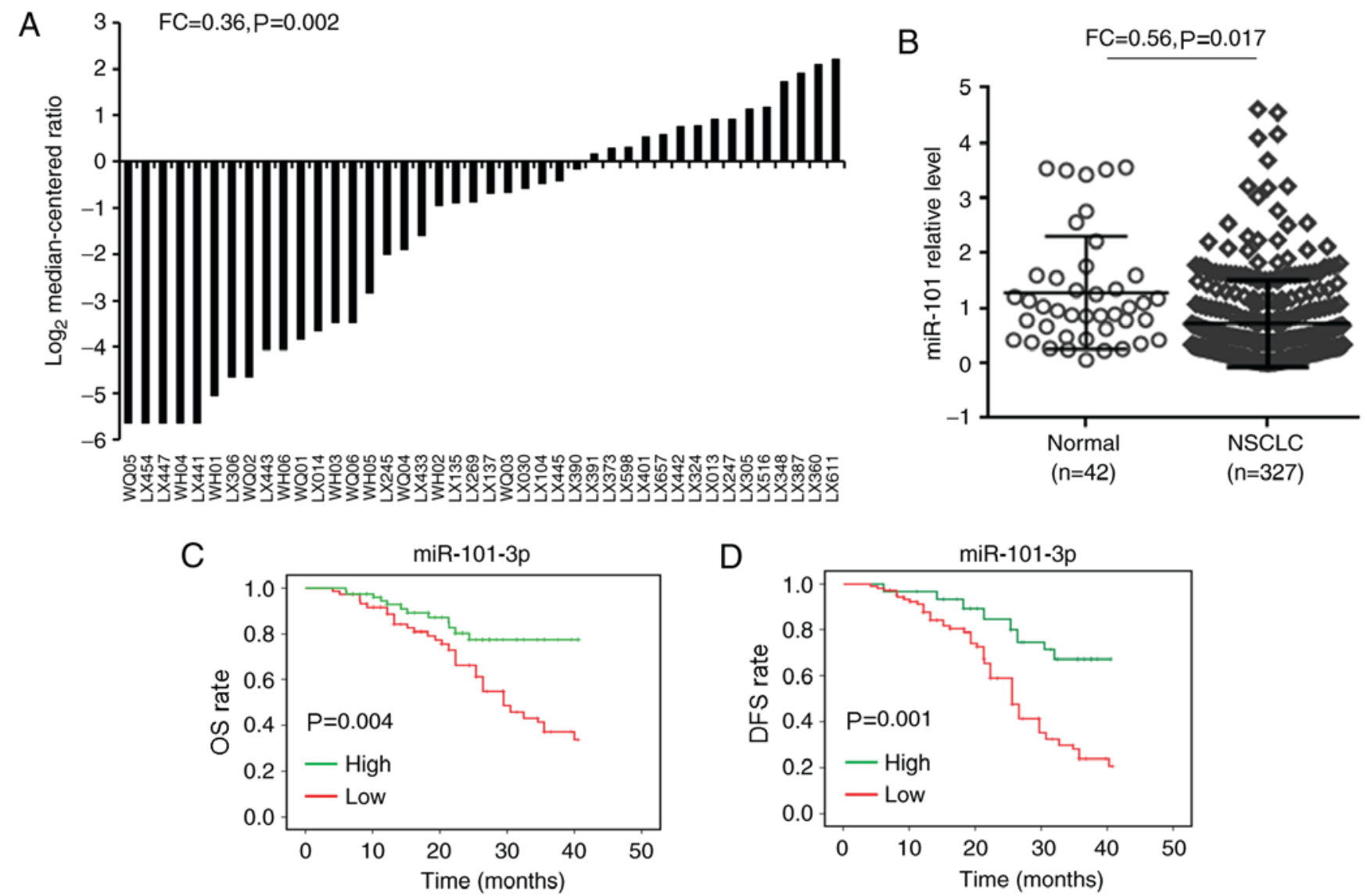

Figure 2. Analysis of miR-101-3p expression in NSCLC and normal lung cancer tissues via quantitative polymerase chain reaction. (A) The expression levels of miR-101-3p in 42 paired NSCLC and adjacent non-cancerous tissues. (B) The miR-101-3p expression in NSCLC ( $\mathrm{n}=327$ ) and paired adjacent non-tumor tissues $(n=42)$ was analyzed. Univariate survival analysis of (C) OS and (D) DFS in NSCLC as determined by Kaplan-Meier plots based on miR-101-3p expression. miR, microRNA; NSCLC, non-small cell lung cancer; FC, fold change; OS, overall survival; DFS, disease-free survival.

Association between clinical characteristics and miR-101-3p expression. Additionally, miR-101-3p expression was analyzed in NSCLC samples based on various clinical characteristics, including age, sex, smoking history, lymph node metastasis, tumor differentiation, histology, TNM stage, invasion of lung membrane, vascular invasion and tumor diameter. Univariate analysis demonstrated that miR-101-3p expression was significantly associated with lymph node metastasis $(\mathrm{P}=0.08)$, tumor diameter $(\mathrm{P}=0.019)$ and TNM stage $(\mathrm{P}=0.036)$ in all patients with NSCLC (Table I). However, no significant association was determined between miR-101-3p expression in NSCLC samples and age, sex, smoking history, tumor differentiation, histology, invasion of the lung membrane or vascular invasion (P>0.05; Table I).

Univariate analysis of prognosis based on various clinical characteristics in patients with NSCLC. To ascertain whether the prognosis of patients with NSCLC was influenced by age, sex, smoking history, lymph node metastasis, tumor differentiation, histology, TNM stage, invasion of lung membrane, vascular invasion, tumor diameter or miR-101-3p expression, univariate analysis with the Kaplan-Meier estimator method was performed. The results demonstrated that lymph node metastasis $(\mathrm{P}=0.042)$, TNM stage $(\mathrm{P}=0.018)$, tumor diameter $(\mathrm{P}=0.013)$ and miR-101-3p expression were significantly associated with $\mathrm{OS}(\mathrm{P}=0.004)$ and DFS $(\mathrm{P}=0.001)$ (Table II; Fig 2).
Univariate Cox regression analysis revealed that lymph-node metastasis [hazard ratio (HR), 1.743; 95\% confidence interval (CI), 1.191-2.421; $\mathrm{P}=0.032$ ], TNM stage $(\mathrm{HR}, 1.562 ; 95 \%$ CI, 1.124-1.962; $\mathrm{P}=0.036)$, tumor diameter (HR, 2.125; 95\% CI, 1.563-3.346; $\mathrm{P}=0.005)$, chemotherapy (HR, 0.778; 95\% CI, 0.469-0.968; $\mathrm{P}=0.026)$ and miR-101 expression $(\mathrm{HR}$, $0.687 ; 95 \%$ CI, 0.498-0.952; $\mathrm{P}=0.003$ ) were also positively significantly associated with a poor prognosis. No significant associations were observed for age, sex, smoking history, tumor differentiation, histology, invasion of lung membrane or vascular invasion (Table III).

Cox regression model analysis of prognosis based on various clinical characteristics in patients with NSCLC. To determine whether miR-101-3p expression levels, in combination with lymph-node metastasis, TNM stage or tumor diameter had prognostic value, multivariate analysis with a Cox regression model was used (Table II). This analysis also indicated that lymph node metastasis (HR, 1.924; 95\% CI, 1.386-3.405; $\mathrm{P}=0.014)$, TNM stage $(\mathrm{HR}, 1.967 ; 95 \% \mathrm{CI}$, 1.544-2.325; $\mathrm{P}=0.018)$ and tumor diameter $(\mathrm{HR}, 2.869 ; 95 \%$ CI, 2.025-3.396; $\mathrm{P}=0.002$ ) were significantly associated with reduced prognosis (Table III). This analysis initially included all of the parameters that were predictive of OS in the univariate analysis of the entire study group as presented in Table II (age, sex, smoking history, lymph-node metastasis, tumor 
Table I. Association between miR-101 expression and clinical characteristics.

\begin{tabular}{|c|c|c|c|}
\hline Factor & No. of patients & miR-101 expression $($ mean $\pm \mathrm{SD})$ & P-value \\
\hline Age (years) & & & 0.668 \\
\hline$\geq 60$ & 167 & $0.703 \pm 0.021$ & \\
\hline$<60$ & 160 & $0.728 \pm 0.059$ & \\
\hline Sex & & & 0.239 \\
\hline Male & 206 & $0.732 \pm 0.045$ & \\
\hline Female & 121 & $0.699 \pm 0.091$ & \\
\hline Smoking history & & & 0.078 \\
\hline Smoked & 136 & $0.682 \pm 0.028$ & \\
\hline Never smoked & 119 & $0.735 \pm 0.071$ & \\
\hline Unknown & 72 & $0.728 \pm 0.031$ & \\
\hline Lymph node metastasis & & & $0.008^{\mathrm{a}}$ \\
\hline Positive & 105 & $0.632 \pm 0.084$ & \\
\hline Negative & 166 & $0.753 \pm 0.054$ & \\
\hline Unknown & 56 & $0.721 \pm 0.029$ & \\
\hline Tumor differentiation & & & 0.097 \\
\hline Poorly & 136 & $0.691 \pm 0.063$ & \\
\hline Moderately & 111 & $0.714 \pm 0.036$ & \\
\hline Well & 80 & $0.722 \pm 0.089$ & \\
\hline Histology & & & 0.604 \\
\hline Adenocarcinoma & 185 & $0.705 \pm 0.039$ & \\
\hline Squamous cell carcinoma & 142 & $0.711 \pm 0.057$ & \\
\hline TNM stage (38) & & & $0.036^{\mathrm{a}}$ \\
\hline III-IV & 158 & $0.681 \pm 0.067$ & \\
\hline I-II & 169 & $0.736 \pm 0.055$ & \\
\hline Invasion of lung membrane & & & 0.063 \\
\hline Positive & 109 & $0.686 \pm 0.029$ & \\
\hline Negative & 168 & $0.725 \pm 0.013$ & \\
\hline Unknown & 50 & $0.721 \pm 0.066$ & \\
\hline Vascular invasion & & & 0.269 \\
\hline Positive & 65 & $0.692 \pm 0.057$ & \\
\hline Negative & 189 & $0.721 \pm 0.033$ & \\
\hline Unknown & 73 & $0.708 \pm 0.037$ & \\
\hline Tumor diameter $(\mathrm{cm})$ & & & $0.019^{\mathrm{a}}$ \\
\hline$\geq 5$ & 186 & $0.677 \pm 0.054$ & \\
\hline$<5$ & 141 & $0.743 \pm 0.065$ & \\
\hline
\end{tabular}

${ }^{\mathrm{a}} \mathrm{P}<0.05$. miR, microRNA; TNM, Tumor-Node-Metastasis; SD, standard deviation.

differentiation, histology, vascular invasion, tumor diameter and invasion of the lung membrane).

Prediction of OS and DFS for patients with NSCLC based on chemotherapy alone or chemotherapy and miR-101-3p expression. There was a statistically significant association between chemotherapy and OS (27.624 \pm 3.858 vs. $31.457 \pm 2.924$, respectively; $\mathrm{P}=0.012)$ and DFS $(26.985 \pm 2.247$ vs. $31.004 \pm 3.357$, respectively; $\mathrm{P}=0.005$ ) in patients with NSCLC. Chemotherapy is the primary adjuvant treatment for the majority of patients with NSCLC undergoing surgery. In the present study, it was determined that adjuvant chemotherapy and high expression of miR-101-3p increased the OS and DFS of patients $(32.738 \pm 3.574$ and $31.946 \pm 3.789$, respectively) compared with non-therapeutic patients with low expression of miR-101-3p (25.352 \pm 2.568 and $25.004 \pm 2.876$, respectively) (Table IV). These data indicated that patients with NSCLC with a high expression of miR-101-3p may have an increased benefit from chemotherapy.

\section{Discussion}

Lung cancer is the most common type of malignant tumor and was reported in 2015 as the leading cause of cancer-associated 
Table II. Univariate analysis of OS and DFS based on patients stratified by clinical characteristics.

\begin{tabular}{|c|c|c|c|c|c|c|c|}
\hline \multirow[b]{2}{*}{ Factor } & \multirow[b]{2}{*}{$\begin{array}{l}\text { No. of } \\
\text { patients }\end{array}$} & \multicolumn{3}{|c|}{ OS time } & \multicolumn{3}{|c|}{ Progression-free survival time } \\
\hline & & $\begin{array}{l}\text { Months } \\
\text { (mean) }\end{array}$ & $\begin{array}{l}95 \% \text { CI } \\
\text { (mean) }\end{array}$ & $\begin{array}{c}\text { P-value } \\
\text { (log-rank test) }\end{array}$ & $\begin{array}{c}\text { Months } \\
\text { (mean) }\end{array}$ & $\begin{array}{l}95 \% \text { CI } \\
\text { (mean) }\end{array}$ & $\begin{array}{c}\text { P-value } \\
\text { (log-rank test) }\end{array}$ \\
\hline Age (years) & & & & & & & 0.331 \\
\hline$\geq 60$ & 167 & 28.065 & $26.945-30.253$ & 0.289 & 28.069 & 26.889-30.453 & \\
\hline$<60$ & 160 & 29.331 & 28.314-31.846 & & 29.564 & $28.651-31.754$ & \\
\hline Sex & & & & & & & 0.822 \\
\hline Male & 206 & 29.652 & $28.773-31.325$ & 0.806 & 30.594 & 28.797-31.393 & \\
\hline Female & 121 & 31.068 & 28.962-32.618 & & 31.056 & $28.845-32.648$ & \\
\hline Smoking history & & & & & & & 0.115 \\
\hline Smoked & 136 & 27.849 & $26.152-29.086$ & 0.109 & 27.654 & $26.465-29.754$ & \\
\hline Never smoked & 119 & 29.659 & $27.854-30.554$ & & 29.435 & $27.784-30.058$ & \\
\hline Unknown & 72 & 28.381 & 26.989-31.062 & & 28.675 & $27.095-31.365$ & \\
\hline Lymph node metastasis & & & & & & & $0.041^{\mathrm{a}}$ \\
\hline Positive & 105 & 26.731 & $24.377-29.501$ & $0.042^{\mathrm{a}}$ & 26.456 & 24.943-29.063 & \\
\hline Negative & 166 & 31.229 & $28.815-33.056$ & & 31.854 & 28.326-33.064 & \\
\hline Unknown & 56 & 28.056 & $26.053-30.434$ & & 28.06 & $26.366-30.582$ & \\
\hline Tumor differentiation (38) & & & & & & & 0.274 \\
\hline Poorly & 136 & 28.851 & $26.826-31.058$ & 0.246 & 28.821 & 26.487-31.348 & \\
\hline Moderately & 111 & 29.348 & $27.854-31.854$ & & 29.815 & $27.145-31.487$ & \\
\hline Well & 80 & 31.857 & $29.581-32.783$ & & 31.825 & 29.747-33.045 & \\
\hline Histology (38) & & & & & & & 0.867 \\
\hline Adenocarcinoma & 185 & 29.744 & $26.451-31.845$ & 0.865 & 28.745 & 26.787-31.165 & \\
\hline Squamous cell carcinoma & 142 & 29.043 & $25.624-32.434$ & & 29.257 & $25.474-32.345$ & \\
\hline TNM stage (38) & & & & & & & $0.012^{\mathrm{a}}$ \\
\hline III-IV & 158 & 26.748 & $24.285-30.647$ & $0.018^{\mathrm{a}}$ & 26.778 & $24.548-30.487$ & \\
\hline I-II & 169 & 31.049 & 28.834-34.415 & & 32.091 & $28.674-34.358$ & \\
\hline Invasion of lung membrane & & & & & & & 0.067 \\
\hline Positive & 109 & 27.995 & $25.453-29.454$ & 0.086 & 27.123 & $25.748-29.486$ & \\
\hline Negative & 168 & 31.412 & $28.542-32.966$ & & 31.545 & 28.364-32.684 & \\
\hline Unknown & 50 & 28.095 & 26.354-30.888 & & 28.157 & 26.387-30.054 & \\
\hline Vascular invasion & & & & & & & 0.066 \\
\hline Positive & 65 & 27.849 & $25.446-29.354$ & 0.072 & 27.048 & 25.487-29.954 & \\
\hline Negative & 189 & 31.069 & $26.878-33.147$ & & 31.157 & $26.748-33.444$ & \\
\hline Unknown & 73 & 29.534 & 27.956-31.259 & & 29.348 & $27.248-31.187$ & \\
\hline Tumor diameter $(\mathrm{cm})$ & & & & & & & $0.009^{\mathrm{a}}$ \\
\hline$\geq 5$ & 186 & 25.386 & $23.685-27.913$ & $0.013^{\mathrm{a}}$ & 24.886 & $23.065-26.648$ & \\
\hline$<5$ & 141 & 31.553 & $27.456-33.546$ & & 30.661 & $28.446-32.596$ & \\
\hline miR-101 expression (median) & & & & & & & $0.001^{\mathrm{a}}$ \\
\hline Low & 163 & 24.154 & $22.314-26.043$ & $0.004^{\mathrm{a}}$ & 24.365 & $22.625-26.443$ & \\
\hline High & 164 & 32.317 & 28.414-34.916 & & 33.053 & 28.456-34.994 & \\
\hline
\end{tabular}

${ }^{\mathrm{a}} \mathrm{P}<0.05$. miR, microRNA; TNM, Tumor-Node-Metastasis; OS, overall survival; CI, confidence interval.

mortality worldwide (26). Drug resistance has remained the primary factor influencing prognosis, therefore the treatment of advanced and metastatic NSCLC remains a notable challenge (27). The recognition of novel biomarkers for prediction of patient response to chemotherapy and prognosis is essential for improving OS and DFS in patients with NSCLC.
As molecular biomarkers, miRNAs serve significant roles in the selection of therapeutic schedules. Their functions as tumor suppressors and oncogenes in human cancer have been previously reported (28). In lung cancer, miRNAs exhibit alterations in expression that predict survival and relapse (29). miR-101 inhibits ovarian cancer cell invasion and 
Table III. Cox regression model analysis for prognosis based on various clinical characteristics in patients with NSCLC.

\begin{tabular}{|c|c|c|c|c|c|c|}
\hline \multirow[b]{2}{*}{ Factor } & \multicolumn{3}{|c|}{ miR-101 univariate analysis } & \multicolumn{3}{|c|}{ miR-101 multivariate analysis } \\
\hline & HR & $95 \% \mathrm{CI}$ & P-value & HR & $95 \% \mathrm{CI}$ & P-value \\
\hline Age & 1.153 & $0.681-1.554$ & 0.093 & 1.176 & $0.699-1.568$ & 0.087 \\
\hline Sex & 0.887 & $0.525-1.115$ & 0.801 & 0.867 & $0.504-1.089$ & 0.542 \\
\hline Smoking history & 1.196 & $0.723-1.587$ & 0.087 & 1.198 & $0.825-1.589$ & 0.061 \\
\hline Lymph-node metastasis & 1.743 & $1.191-2.421$ & $0.032^{\mathrm{a}}$ & 1.924 & $1.386-3.405$ & $0.014^{\mathrm{a}}$ \\
\hline Tumor differentiation & 1.154 & $0.961-1.224$ & 0.224 & 1.168 & $0.979-1.231$ & 0.201 \\
\hline Histology & 0.835 & $0.698-1.142$ & 0.324 & 0.831 & $0.624-1.104$ & 0.265 \\
\hline TNM stage & 1.562 & $1.124-1.962$ & $0.036^{\mathrm{a}}$ & 1.967 & $1.544-2.325$ & $0.018^{\mathrm{a}}$ \\
\hline Invasion of lung membrane & 1.164 & $1.006-1.453$ & 0.089 & 1.196 & $1.075-1.469$ & 0.066 \\
\hline Vascular invasion & 1.169 & $1.021-1.468$ & 0.088 & 1.182 & $1.069-1.494$ & 0.059 \\
\hline Tumor diameter & 2.125 & $1.563-3.346$ & $0.005^{\mathrm{a}}$ & 2.869 & $2.025-3.396$ & $0.002^{\mathrm{a}}$ \\
\hline Chemotherapy & 0.778 & $0.469-0.968$ & $0.026^{\mathrm{a}}$ & 0.559 & $0.374-0.786$ & $0.006^{\mathrm{a}}$ \\
\hline miR-101 expression & 0.687 & $0.498-0.952$ & $0.003^{\mathrm{a}}$ & & & \\
\hline
\end{tabular}

${ }^{\text {a }} \mathrm{P}<0.05$. miR, microRNA; CI, confidence interval; TNM, Tumor-Node-Metastasis.

Table IV. OS and DFS of patients with NSCLC based on chemotherapy alone or chemotherapy and miR-101 expression.

\begin{tabular}{|c|c|c|c|c|c|c|c|}
\hline \multirow[b]{2}{*}{ Characteristics } & \multirow{2}{*}{$\begin{array}{l}\text { No. of } \\
\text { patients }\end{array}$} & \multicolumn{3}{|c|}{ OS } & \multicolumn{3}{|c|}{ DFS } \\
\hline & & Mean \pm SD & $95 \% \mathrm{CI}$ & $\mathrm{P}$-value & Mean \pm SD & $95 \% \mathrm{CI}$ & $\mathrm{P}$-value \\
\hline Chemotherapy & & & & 0.012 & & & 0.005 \\
\hline Yes & 231 & $31.457 \pm 2.924$ & $28.728-34.632$ & & $31.004 \pm 3.357$ & 28.244-33.148 & \\
\hline No & 96 & $27.624 \pm 3.858$ & $25.741-29.478$ & & $26.985 \pm 2.247$ & $25.311-28.634$ & \\
\hline $\begin{array}{l}\text { Chemotherapy \& miR-101 } \\
\text { expression }\end{array}$ & & & & 0.001 & & & $<0.001$ \\
\hline $\mathrm{P} \& \mathrm{H}$ & 65 & $32.738 \pm 3.574$ & $30.469-34.774$ & & $31.946 \pm 3.789$ & $28.158-33.564$ & \\
\hline$N \& L$ & 87 & $25.352 \pm 2.568$ & 22.914-27.353 & & $25.004 \pm 2.876$ & $23.043-26.965$ & \\
\hline
\end{tabular}

P \& H, chemotherapy and high miR-101 expression; N \& L, no chemotherapy and low miR-101 expression. OS, overall survival; DFS, disease-free survival; miR, microRNA; SD, standard deviation; CI, confidence interval.

proliferation by downregulating the expression of suppression of cytokine signaling 2 (30), and also has implications in suppressing the spread of a number of tumor types, including chondrosarcoma (31), thyroid cancer (32), breast cancer (33) and hepatocellular carcinoma (34). It has been reported that miR-101 inhibits cell proliferation and invasion of lung cancer by regulating cyclooxygenase-2 (35). Additionally, low expression of miR-101 in lung cancer has been demonstrated to inhibit the invasion of lung cancer by regulating its target gene enhancer of zerte 2 polycomb repressive complex 2 subunit (36).

miR-101-3p is a member of the miR-101 family and inhibits the metastasis-associated lung adenocarcinoma transcript 1 (MALAT-1)-induced activation of the phosphoinositide 3-kinase/Akt signaling pathway, resulting in the inhibition of NSCLC growth and metastasis (16). It is notable that miR-101-3p expression in NSCLC cells was significantly reduced, whereas MALAT-1 expression was significantly increased. Furthermore, high expression of miR-101-3p inhibits the proliferation, migration and invasion of NSCLC (37). In the present study, significantly reduced levels of miR-101-3p was observed in patients with NSCLC, compared with healthy controls. The level of miR-101-3p expression in NSCLC was determined to be associated with OS and DFS, indicating that miR-101-3p may serve as a prognostic biomarker in patients with NSCLC. The analysis of a number of clinical factors, including tumor diameter, TNM stage and lymph node metastasis, demonstrated associations with OS and DFS. Notably, as an independent parameter, miR-101-3p expression levels in NSCLC also affected prognosis and survival.

miR-101-3p is a valuable prognostic predictor and therapeutic target of clinical chemotherapy. The present analysis determined that a high level of expression of miR-101-3p in patients with NSCLC who had undergone routine 
chemotherapy was positively associated with OS and DFS rates. This indicated that patients with NSCLC with high levels of miR-101-3p expression may have improved benefit from chemotherapy. In brief, miR-101-3p was significantly downregulated in NSCLC, which increased the OS and DFS rates of patients receiving adjuvant chemotherapy. Based on these results, whether the miR-101-3p expression level may serve as a biomarker for chemotherapy use in patients with NSCLC should be investigated, and therefore may be a valuable and promising biomarker for this disease. However, the molecular and pathophysiological mechanisms of miR-101-3p in NSCLC are not fully understood, and will be assessed in subsequent studies. The present study had a number of limitations. For example, this is a retrospective study and only one marker was addressed. There are other markers or associated pathways that must be studied. In the future, multicenter studies regarding miR-101-3p in NSCLC should be performed.

In conclusion, the present data confirmed that with adjuvant chemotherapeutic treatment the median OS and DFS rate of patients improved. The analyses demonstrated that low expression of miR-101-3p, together with adjuvant chemotherapy, notably improved the OS and DFS of patients with NSCLC. The use of miR-101-3p as a specific and sensitive biomarker may be suitable for prediction of therapeutic responses in patients with advanced NSCLC, which may result in a superior level of personalized therapy. Therefore, miR-101-3p may be considered as a potential biomarker for chemosensitivity in the tumors of patients with NSCLC.

\section{Acknowledgements}

We would like to thank the experimental support of Central Laboratory for Medical Research, Shanghai Tenth People's Hospital (Shanghai, China).

\section{Funding}

The present study was partially supported by grants from the National Natural Science Foundation of China (grant nos. 81472202, 81772932, 81201535, 81302065, 81301993, 81702243,81260345 and 81372175), Shanghai Natural Science Foundation (grant nos. 12ZR1436000 and 16ZR1428900), Shanghai Municipal Commission of Health and Family Planning (grant nos. 201540228 and 201440398), Program of Shanghai Subject Chief Scientist (grant no. 04.01.13.059), The Fundamental Research Funds for the Central Universities (grant no. 22120170212 and 22120170117), Clinical Research Special Foundation of the Wu Jieping Medical Foundation (grant no. 320.6750.14326) and Nantong Science and Technology Project (grant no. yyz15026).

\section{Availability of data and materials}

The datasets used and/or analyzed during the current study are available from the corresponding author on reasonable request.

\section{Authors' contributions}

HML, WWY, YSM, FY, JBL, and DF designed the study. HML, WWY, FY, YSM, WTX, HWF, ZWL, LKH, WW, JJJ,
ZYC, MXS, YCS, LC, CYJ, GXL and DF performed the qPCR experiments. HML, WWY, FY, YSM, WTX, LKH, WW, MXS, HQY, CZ, LC, CYJ, GXL, CYW and DF performed the statistical analyses and interpreted the data. FY, YSM, ZWL, LKH, WW, HML, JJJ, MXS, LC, CYJ, GXL, CYW, XJZ, JBL, and DF are involved in patient recruitment. FY, YSM, ZWL, CYW, JBL, and DF contributed to study materials and consumables. FY, YSM, ZWL, WTX and DF wrote the manuscript. HML, WWY, YSM, WW and FY contributed equally to this work. All authors agreed with the results and conclusions.

\section{Ethics approval and consent to participate}

The present study was approved by the Ethics Committee of Shanghai Tenth People's Hospital, Tongji University School of Medicine (approval no. SHSY-IEC-pap-15-18). Each participant provided signed informed consent prior to participate in the present study. Patients or their legal surrogates provided signed informed consent for the surgical procedures.

\section{Patient consent for publication}

Not applicable.

\section{Competing interests}

The authors declare that they have no competing interests.

\section{References}

1. Lu G, Fu D, Jia C, Chai L, Han Y, Liu J, Wu T, Xie R, Chang Z, Yang H, et al: Reduced miR-105-1 levels are associated with poor survival of patients with non-small cell lung cancer. Oncol Lett 14: 7842-7848, 2017.

2. Zhang T, Rong N, Chen J, Zou C, Jing H, Zhu X and Zhang W: SIRT1 expression is associated with the chemotherapy response and prognosis of patients with advanced NSCLC. PLoS One 8: e79162, 2013.

3. Hou L, Luo P, Ma Y, Jia C, Yu F, Lv Z, Wu C and Fu D: MicroRNA-125a-3p downregulation correlates with tumorigenesis and poor prognosis in patients with non-small cell lung cancer. Oncol Lett 14: 4441-4448, 2017.

4. Hou LK, Ma YS, Han Y, Lu GX, Luo P, Chang ZY, Xie RT, Yang HQ, Chai L, Cai MX, et al: Association of microRNA-33a molecular signature with non-small cell lung cancer diagnosis and prognosis after chemotherapy. PLoS One 12: e0170431, 2017.

5. Yu F, Liu JB, Wu ZJ, Xie WT, Zhong XJ, Hou LK, Wu W, Lu HM, Jiang XH, Jiang JJ, et al: Tumor suppressive microRNA-124a inhibits stemness and enhances gefitinib sensitivity of non-small cell lung cancer cells by targeting ubiquitin-specific protease 14 . Cancer Lett 427: 74-84, 2018.

6. Ma YS, Wu TM, Lv ZW, Lu GX, Cong XL, Xie RT, Yang HQ, Chang ZY, Sun R, Chai L, et al: High expression of miR-105-1 positively correlates with clinical prognosis of hepatocellular carcinoma by targeting oncogene NCOA1. Oncotarget 8 : 11896-11905, 2017.

7. Xu C, Haque F, Jasinski DL, Binzel DW, Shu D and Guo P: Favorable biodistribution, specific targeting and conditional endosomal escape of RNA nanoparticles in cancer therapy. Cancer Lett 414: 57-70, 2018.

8. Salzman DW, Nakamura K, Nallur S, Dookwah MT, Metheetrairut C, Slack FJ and Weidhaas JB: miR-34 activity is modulated through 5'-end phosphorylation in response to DNA damage. Nat Commun 7: 10954, 2016.

9. Persson H, Søkilde R, Häkkinen J, Pirona AC, Vallon-Christersson J, Kvist A, Mertens F, Borg A, Mitelman F, Höglund $\mathrm{M}$ and Rovira C: Frequent miRNA-convergent fusion gene events in breast cancer. Nat Commun 8: 788, 2017. 
10. Xie RT, Cong XL, Zhong XM, Luo P, Yang HQ, Lu GX, Luo P, Chang ZY, Sun R, Wu TM, et al: MicroRNA-33a downregulation is associated with tumorigenesis and poor prognosis in patients with hepatocellular carcinoma. Oncol Lett 15: 4571-4577, 2018

11. Mi Y, Zhang D, Jiang W, Weng J, Zhou C, Huang K, Tang H, Yu Y, Liu X, Cui W, et al: miR-181a-5p promotes the progression of gastric cancer via RASSF6-mediated MAPK signalling activation. Cancer Lett 389: 11-22, 2017.

12. Cutrona G, Matis S, Colombo M, Massucco C, Baio G, Valdora F, Emionite L, Fabris S, Recchia AG, Gentile M, et al: Effects of miRNA-15 and miRNA-16 expression replacement in chronic lymphocytic leukemia: Implication for therapy. Leukemia 31: 1894-1904, 2017.

13. Linnstaedt SD, Gottwein E, Skalsky RL, Luftig MA and Cullen BR: Virally induced cellular microRNA miR-155 plays a key role in B-cell immortalization by Epstein-Barr virus. J Virol 84: 11670-11678, 2010.

14. Yanaihara N, Caplen N, Bowman E, Seike M, Kumamoto K, Yi M, Stephens RM, Okamoto A, Yokota J, Tanaka T, et al: Unique microRNA molecular profiles in lung cancer diagnosis and prognosis. Cancer Cell 9: 189-198, 2006.

15. Othman $\mathrm{N}$ and Nagoor NH: miR-608 regulates apoptosis in human lung adenocarcinoma via regulation of AKT2. Int J Oncol 51: 1757-1764, 2017.

16. Zhang X, He X, Liu Y, Zhang H, Chen H, Guo S and Liang Y: MiR-101-3p inhibits the growth and metastasis of non-small cell lung cancer through blocking PI3K/AKT signal pathway by targeting MALAT-1. Biomed Pharmacother 93: 1065-1073, 2017.

17. Wang $\mathrm{H}$, Wang L, Zhang G, Lu C, Chu H, Yang R and Zhao G: MALAT1/miR-101-3p/MCL1 axis mediates cisplatin resistance in lung cancer. Oncotarget 9: 7501-7512, 2017.

18. Liu C, Fu H, Liu X, Lei Q, Zhang Y, She X, Liu Q, Liu Q, Sun Y, Li G and Wu M: LINC00470 coordinates the epigenetic regulation of ELFN2 to distract GBM cell autophagy. Mol Ther 26: 2267-2281, 2018.

19. Wakasugi H, Takahashi H, Niinuma T, Kitajima H, Oikawa R, Matsumoto N, Takeba Y, Otsubo T, Takagi M, Ariizumi Y, et al: Dysregulation of miRNA in chronic hepatitis B is associated with hepatocellular carcinoma risk after nucleos(t)ide analogue treatment. Cancer Lett 434: 91-100, 2018.

20. Cao L, Chen Y, Zhang M, Xu DQ, Liu Y, Liu T, Liu SX and Wang P: Identification of hub genes and potential molecular mechanisms in gastric cancer by integrated bioinformatics analysis. PeerJ 6: e5180, 2018.

21. Keller A, Leidinger P, Vogel B, Backes C, ElSharawy A, Galata V, Mueller SC, Marquart S, Schrauder MG, Strick R, et al: miRNAs can be generally associated with human pathologies as exemplified for miR-144. BMC Med 12: 224, 2014

22. Leidinger P, Brefort T, Backes C, Krapp M, Galata V, Beier M, Kohlhaas J, Huwer H, Meese E and Keller A: High-throughput qRT-PCR validation of blood microRNAs in non-small cell lung cancer. Oncotarget 7: 4611-4623, 2016.

23. Fujita Y, Yagishita S, Hagiwara K, Yoshioka Y, Kosaka N, Takeshita F, Fujiwara T, Tsuta K, Nokihara H, Tamura T, et al: The clinical relevance of the miR-197/CKS1B/STAT3-mediated PD-L1 network in chemoresistant non-small-cell lung cancer. Mol Ther 23: 717-727, 2015.

24. Chen C, Ridzon DA, Broomer AJ, Zhou Z, Lee DH, Nguyen JT, Barbisin M, Xu NL, Mahuvakar VR, Andersen MR, et al: Real-time quantification of microRNAs by stem-loop RT-PCR. Nucleic Acids Res 33: e179, 2005.
25. Livak KJ and Schmittgen TD: Analysis of relative gene expression data using real-time quantitative PCR and the 2(-Delta Delta (T)) method. Methods 25: 402-408, 2001.

26. Liang Z, Kong R, He Z, Lin LY, Qin SS, Chen CY, Xie ZQ, Yu F, Sun GQ, Li CG, et al: High expression of miR-493-5p positively correlates with clinical prognosis of non small cell lung cancer by targeting oncogene ITGB1. Oncotarget 8: 47389-47399, 2017.

27. Zhang B, Fu D, Xu Q, Cong X, Wu C, Zhong X, Ma Y, Lv Z, Chen F, Han L, et al: The senescence-associated secretory phenotype is potentiated by feedforward regulatory mechanisms involving Zscan4 and TAK1. Nat Commun 9: 1723, 2018

28. Huang Q, Zhang XW, Ma YS, Lu GX, Xie RT, Yang HQ, Lv ZW, Zhong XM, Liu T, Huang SX, et al: Up-regulated microRNA-299 corrected with poor prognosis of glioblastoma multiforme patients by targeting ELL2. Jpn J Clin Oncol 47: 590-596, 2017.

29. Chang TH, Tsai MF, Gow CH, Wu SG, Liu YN, Chang YL, Yu SL, Tsai HC, Lin SW, Chen YW, et al: Upregulation of microRNA-137 expression by Slug promotes tumor invasion and metastasis of non-small cell lung cancer cells through suppression of TFAP2C. Cancer Lett 402: 190-202, 2017.

30. Zheng HB, Zheng XG and Liu BP: miRNA-101 inhibits ovarian cancer cells proliferation and invasion by down-regulating expression of SOCS-2. Int J Clin Exp Med 8: 20263-20270, 2015.

31. Tsai CH, Yang DY, Lin CY, Chen TM, Tang CH and Huang YL: Sphingosine-1-phosphate suppresses chondrosarcoma metastasis by upregulation of tissue inhibitor of metalloproteinase 3 through suppressing miR-101 expression. Mol Oncol 11: 1380-1398, 2017.

32. Wang C,Lu S, Jiang J, Jia X, Dong X and Bu P: Hsa-microRNA-10 suppresses migration and invasion by targeting Racl in thyroid cancer cells. Oncol Lett 8: 1815-1821, 2014.

33. Li JT, Jia LT, Liu NN, Zhu XS, Liu QQ, Wang XL, Yu F, Liu YL, Yang AG and Gao CF: MiRNA-101 inhibits breast cancer growth and metastasis by targeting $\mathrm{CX}$ chemokine receptor 7 . Oncotarget 6: 30818-30830, 2015.

34. ShakerO, Alhelf M, Morcos G and Elsharkawy AL: miRNA-101-1 and miRNA-221 expressions and their polymorphisms as biomarkers for early diagnosis of hepatocellular carcinoma. Infect Genet Evol 51: 173-181, 2017.

35. Lv P, Zhang P, Li X and Chen Y: Micro ribonucleic acid (RNA)-101 inhibits cell proliferation and invasion of lung cancer by regulating cyclooxygenase-2. Thorac Cancer 6: 778-784, 2015.

36. Lei YM, Zu YF, Wang J, Bai S, Shi YF, Shi R, Duan J, Cui D, Chen J, Xiang Y and Dong J: Interleukin-1 $\beta$-mediated suppression of microRNA-101 and upregulation of enhancer of zeste homolog 2 is involved in particle-induced lung cancer. Med Oncol 32: 387, 2015.

37. Wan X, Kong Z, Chu K, Yi C, Hu J, Qin R, Zhao C, Fu F, $\mathrm{Wu} \mathrm{H}, \mathrm{Li}$ Y and Huang Y: Co-expression analysis revealed PTCH1-3'UTR promoted cell migration and invasion by activating miR-101-3p/SLC39A6 axis in non-small cell lung cancer: Implicating the novel function of PTCH1. Oncotarget 9: 4798-4813, 2017

38. Edge SB and Compton CC: The American Joint Committee on Cancer: The 7th edition of the AJCC cancer staging manual and the future of TNM. Ann Surg Oncol 17: 1471-1474, 2010.

This work is licensed under a Creative Commons Attribution-NonCommercial-NoDerivatives 4.0 International (CC BY-NC-ND 4.0) License. 